\title{
SOB O REINADO DA PESTE: UMA ANÁLISE DO CONTO "O REI PESTE"
}

Ana Maria Zanoni da Silva

Recebido em 01 nov 2020. Ana Maria Zanoni da Silva é pós-doutorada pela Aprovado em 14 dez 2020. Universidade Federal de São Paulo, campus Guarulhos, professora do Instituto Municipal de Ensino Superior de Bebedouro e pesquisadora do grupo de pesquisa Língua e literatura: interdisciplinaridade e docência. http://lattes.cnpq.br/5454369183664327 https://orcid.org/0000-0002-6655-0748 anazanoni_@hotmail.com

Resumo: Medo é um dos sentimentos que achincalha a alma naqueles períodos em que as grandes epidemias assolam a humanidade. Não se trata apenas do medo perante ao que causa a doença, mas também o medo do outro, dos corpos contaminados, das dores, das angústias decorrentes do sentimento de impotência perante o mundo alheado, convertido em palco para um espetáculo horrível, do qual os protagonistas não retornam. Nesse sentido, este trabalho tem por objetivo analisar o conto "O Rei Peste", publicado no Southern Literary Messenger, em setembro de 1835, com o título de King Pest the First. A Tale Containing an Allegory, a fim de demostrar como Edgar Allan Poe, ao valer-se da imagem do corpo grotesco, transfigura o tema peste em ficção e em que medida essa transfiguração, ao instaurar uma atmosfera de horror questiona a ordem imposta e mostra falhas e 
incongruências presentes nas formas de controle do contágio, apontando para as transformações que o surto de peste impõe a sociedade.

Palavras-chave: Corpos Grotescos. Ordem Imposta. Peste. Poe.

Abstract: Fear is one of the feelings that scare the soul in those periods when the great epidemics are plaguing humanity. It is not just the fear of what causes the disease, but also the fear of the other, of the contaminated bodies, of the pains, of the anguish resulting from the feeling of powerless in the face of the alienated world, converted into a stage for a horrible spectacle, from which protagonists do not return. In this sense, this work aims to analyze the tale King Pest, published in Southern Literary Messenger, in September 1835, with the title of King Pest the First. The Tale Containing an Allegory, in the light of Bakhtin's theoretical assumptions, in order to demonstrate how Edgar Allan Poe, when using the image of the grotesque body, transforms the pest theme into fiction and to what extent this transfiguration, by establishing an atmosphere in horror, questions the imposed order and shows flaws and incongruities present in the ways of controlling contagion, pointing to the transformations that the pest outbreak imposes on society.

Keywords: Epidemics. Grotesque bodies. Imposed order. Poe.

\section{INTRODUÇÃO}

Medo é um dos sentimentos que achincalha a alma naqueles períodos em que as grandes epidemias assolam a humanidade. Não se trata apenas do medo perante ao que causa a doença, mas também o medo do outro, dos corpos contaminados, das dores, das angústias decorrentes do sentimento de impotência perante o 
mundo alheado, convertido em palco para um espetáculo do qual muitos protagonistas não retornam.

Esse sentimento aterrorizante, decorrente de guerras e surtos epidêmicos, tem servido de tema para a criação ficcional entre os textos mais conhecidos encontram-se: Decameron (134952) de Bocaccio e A Journal of the Plague Year (1722) de Daniel Defoe. Boccacio estrutura sua obra com cem narrativas contadas por um grupo de sete moças e três rapazes que se abrigaram em um castelo próximo a Florença, com o objetivo de fugir da peste negra. As narrativas retratam a peste trazendo à tona as formas de manifestação dos sintomas e também a sensação de impotência perante aos horrores de uma morte causada por um inimigo que a medicina e a religião não conseguiam explicar tão pouco controlar. E Defoe relata, cronologicamente, as experiências vivenciadas por um homem durante o ano de 1665, período em que Londres foi devastada pela peste negra, delineando um assombroso retrato da cidade e tecendo comentários a respeito daquilo que se deve evitar para não ser contaminado.

Ao abordar a obra de Defoe, Jennifer Cooke (2009) chama a atenção para o fato de que o protagonista H.F. descreve e critica as medidas utilizadas para conter a doença por meio da instituição de quarentena, detalha a forma de descarte dos mortos e também as atitudes de religiosos e cidadãos tanto em relação ao surto quanto em relação aos demais.

Sendo assim, Jennifer Cooke (2009) afirma que a ficção ocupa uma posição privilegiada que Ihe permite abordar os traumas decorrentes da grande quantidade de mortes, do medo do contágio 
e do horror que os corpos acometidos pelas epidemias suscitam. E devido a linha tênue que separa o universo ficcional da história, as narrativas ficcionais podem contribuir para a compreensão da história, bem como as delimitações que estruturam tal relação.

Além dessas obras retratarem o isolamento, os horrores, o medo e a perda de vidas que a peste imputou sobre a Europa, elas também descrevem a deformidade dos corpos decorrentes dos bulbões, ou seja, do aumento das glândulas linfáticas que fazem as pessoas adotarem uma postura deformada para reduzir a pressão e aliviar a dor. A dimensão e a cor e a laceração dos bulbões, tal como ocorreu em 1665 como forma de tratamento, tornam os corpos disformes e horripilantes. Essas obras retratam o isolamento, os horrores, o medo e a perda de vidas que a peste e a guerra imputaram sobre a Europa. As epidemias, ao longo dos tempos, acometem a humanidade e evidenciam as transformações da sociedade e, sobretudo, fazem notar a necessidade de revisão e adequação da ordem imposta.

Em uma Nota Preliminar aos contos de Terror, Mistério e Morte, reunidos na coletânea Edgar A. Poe: Ficção Completa, Poesia \& Ensaios, Oscar Mendes afirma que nos contos dessa categoria o medo é um sentimento real: "O medo, pois que existe nos seus contos é um medo real, autêntico, sentido, arraigado" (MENDES, 1997, p. 189).

Mediantes tais constatações, este trabalho tem por objetivo analisar o "O Rei Peste", publicado no Southern Literary Messenger, em setembro de 1835, com o título de King Pest the First. A Tale Containing an Allegory, a fim de demostrar como Edgar Allan Poe, 
ao valer-se da imagem do corpo grotesco, transfigura o tema da peste em ficção e em que medida essa transfiguração, ao instaurar uma atmosfera de horror, questiona a ordem imposta e mostra falhas e incongruências presentes nas formas de controle do contágio, apontando para as transformações que o surto de peste impõe a sociedade.

\section{SOB O REINADO DA PESTE}

Na Idade Média, a morte passou a fazer parte dos acontecimentos humanos de forma terrível e em amplas proporções. Os acontecimentos terríveis e o horror espalhado pela peste negra fizeram da morte uma presença constante na vida de milhares de pessoas. Os corpos descarnados em putrefação e os seres magérrimos pela falta de hábitos de higiene e alimentação criaram um cenário de horror. Foi desse cosmo que Edgar Allan Poe abstraiu os motivos que compõem a trama do conto "King Pest The First. A Tale Containing An Allegory", publicado pela primeira vez em setembro de 1835, no Southern Literary Messenger, jornal do qual Poe foi redator. Em 1839, na qualidade de redator do Gentleman's Magazine de Filadélfia, Poe organiza vinte e cinco contos em uma coletânea em dois volumes sob o título de Tales of the Grotesque and Arabesque e nela inclui o referido conto.

O conto em apreço, segundo Sova (2001, p. 123) trata-se de uma das narrativas mais intrigantes, devido a mescla de horror com humor, com a qual Poe aborda um dos períodos, no qual a peste negra assolou a Inglaterra durante o reinado de Eduardo III. Devido a essa mescla de horror e humor, Robert Louis Stevenson (apud 
Sova, 2001, p. 123) criticou Poe, ao afirmar que: "Aquele que podia escrever 'Rei Peste' havia cessado de ser um ser humano".

Ao abordar a coletânea Tales of the Grotesque and Arabesque, Leon Howard afirma que Poe classifica de grotescos aqueles contos que "obtêm seu efeito por meio de um senso de humor sinistro e irônico" (1960, p. 114 -116). Ainda no Prefácio da coletânea Tales of the Grotesque and Arabesque, Poe expõe sua visão crítica a respeito do teor das histórias ali copiladas, designando-as por meio dos epítetos grotescos e arabescos. Segundo afirma Wolfgang Kayser, o termo grotesco foi utilizado por Poe em dois planos, ou seja, um em que se designa "uma situação concreta, na qual a ordem do mundo saiu fora dos eixos", e o outro em que se qualifica o teor de histórias inteiras, "onde se narra o horripilante inconcebível, o noturno inexplorável e, às vezes, o fantasticamente bizarro" (1986, p. 76).

A coexistência desses dois planos motivou a crítica de Stevenson, uma vez que a riqueza de imagens presente, tanto nos corpos das personagens quanto na caracterização do cenário em que os fatos ocorrem, remetem aos horrores decorrentes da putrefação de corpos, para os quais não houve um funeral nos moldes previstos pela sociedade da época. Desse modo, a compreensão da totalidade das imagens presentes no conto, requer uma leitura focada na constituição do corpo e do espaço de modo grotesco, uma vez que Poe configura um cosmo nos moldes daqueles descritos por Bakhtin (1999), em um regime social no qual os aspectos sérios e cômicos do homem e do mundo eram igualmente sagrados e oficiais.

Esse mundo paralelo situado dentro do espaço delimitado pela peste oferece uma visão de mundo na qual a morte fora convertida 
em um rei burlesco cujo discurso empolado não passa de blasfémia. A atmosfera horripilante é atenuada pela ambivalência das imagens inseridas na trama, por meio da escolha de um tom humorístico. Essa combinação permite a Poe explorar o tema da peste valendose da imagem grotesca do corpo o que lhe permite tratar em tom humorístico a decadência do Rei Peste I e seus familiares. A imagem do rei e sua corte se decompondo em decorrência do acometimento pela peste cria um espetáculo carnavalesco da morte do qual nem mesmo os nobres conseguem escapar, pois não há fronteiras espaciais para a morte, já que esta faz parte do ciclo natural da vida.

O tom humorístico conferido à narrativa, cuja trama articula a história vivenciada por dois marujos recém chegados a Londres, durante o reinado de Eduardo III, no navio que tem por nome Free and Easy, se deve também a embriaguez dos marinheiros. Advindos de um espaço, no qual prevalecem a liberdade e alegria, tal como aponta o nome da embarcação, os dois marinheiros entram em Londres, cidade em que reinam a instauração da autoridade real, do distanciamento e do horror decorrentes das devastações causadas pela peste negra. Ao confrontar o espaço de liberdade com o do reinado de Eduardo III, Poe insere na narrativa personagens, cujos corpos revelam aspectos grotescos e instauram, na trama, uma ordem não oficial, por meio da qual os domínios do Rei Peste I foram transformados em alegoria do reinado oficial.

Nesse reino às avessas, o leitor toma ciência dos fatos pela voz do narrador extradiegético que, no início da narrativa, valendose de focalização externa, caracteriza os personagens por meio da descrição de seus corpos. Legs, o mais velho da dupla, é 
extremamente magro e sua altura atinge a proporção de "pau de bujarrona", com cerca de dois metros e dez centímetros de altura.

A descrição do rosto dele com maçãs salientes, "grande nariz adunco, queixo fugidio, pesado maxilar inferior e grandes olhos protuberantes e brancos" (POE, 1987, p. 213-214), faz referência ao traje usado pelos médicos, durante o século XVII, para cuidar das vítimas da peste. Tratava-se de um traje composto por uma máscara de couro, da qual se destacava um grande nariz, semelhante ao bico de pássaro, dois orifícios por onde se viam os olhos de quem o vestisse e cobria o corpo da cabeça aos pés. Nesse traje, os médicos eram convertidos em uma figura sinistra e horripilante. A descrição do rosto de Legs explora os traços contidos na máscara e fazem dele uma imagem caricata grotesca dos médicos da peste, uma vez que o nariz dele foi convertido em bico.

Segundo Chevalier e Gheerbrant (1995, p. 743), o nariz, órgão do olfato, que descobre simpatias e antipatias, guia os desejos, as palavras e as pernas e, juntamente com as pernas, o sexo e a língua, é um dos trabalhadores responsáveis pelo bom funcionamento da sociedade. A simbologia que o nariz encerra amalgamada à proporção das pernas faz de Legs uma metáfora da restituição da ordem social e será por meio das ações dele que o reinado do Rei Peste I terá seu fim. A força de Legs promove a reordenação do reino às avessas, pois a enchente afoga os membros do parlamento instaurado sob os domínios do Rei Peste I. Segundo afirma Bakhtin:

O universo do grotesco romântico se apresenta geralmente como terrível e alheio ao homem. Tudo o que é costumeiro, banal, habitual, reconhecido por todos, torna-se subitamente insensato, 
duvidoso, estranho e hostil ao homem. [...] Ao contrário, o grotesco medieval e renascentista, associado à cultura cômica popular, representa o terrível através dos espantalhos cômicos, isto é, na forma do terrível vencido pelo riso. O terrível adquire sempre um tom de bobagem alegre. (1999, p. 34)

A caracterização de Legs suscita o terror, ao colocar em cena uma personagem que corporifica o traje costumeiro do médico de tempos remotos, e ao mesmo tempo desperta o cômico, pois o marinheiro transforma-se em um tipo de espantalho, cuja imagem cômica vence o terrível ao revelar o lado risível, que se mantinha oculto sob os falsos mecanismos de segurança para se evitar o contágio da peste.

Ao contrário de Legs, Hugh Tarpaulin tem um metro e vinte de estatura, pernas arqueadas, corpo rechonchudo, braços curtos e grossos, semelhantes a barbatanas de tartaruga-marinha.

Um par de pernas atarracadas e arqueadas suportava-Ihe o corpo pesado e rechonchudo, enquanto os braços, descomunalmente curtos e grossos, de punhos incomuns, pendiam balouçantes dos lados como as barbatanas de uma tartaruga marinha. Os olhos pequenos, de cor imprecisa, brilhavam-Ihe encravados fundamente nas órbitas. O nariz se afundava na massa de carne, que Ihe envolvia a cara redonda, cheia, purpurina. O grosso lábio superior descansava sobre o inferior, ainda mais carnudo, com um ar de complacente satisfação pessoal, mais acentuada pelo hábito que tinha o dono de lamber os beiços de vez em quando. (POE, 1997, p. 214)

O nome de Hugh Tarpaulin, revela-se significativo no desenrolar da trama, pois trata-se de um trocadilho com a palavra 
"tar", que significa piche e também marinheiro. Por Tarpulin, entende-se também um tipo de capa encerada para proteger da água. O aspecto de "encerado", ou seja de engordurado e brilhoso combina com a descrição física da personagem, um anão de corpo pesado. Os traços grotescos do corpo se fazem notar também no rosto dessa personagem, descrito como gordo e protuberante, com olhos pequenos, nariz encoberto por uma massa de carne e lábios que atingem a proporção de beiços, os quais inserem a personagem na escala natural na categoria dos símios, um típico companheiro dos marujos.

Tal como afirma Bakhtin, o nariz e a boca têm um papel importante na construção da imagem grotesca do corpo, principalmente, "quando se transformam em figuras de animais ou de coisas" (1999, p. 276). Embora sejam caracterizados por meio do rebaixamento do homem à categoria de animais, os marinheiros adquirem a confiança e a aceitação do leitor. Legs tem um caráter sério, pois, "a expressão de sua fisionomia, embora repassada duma espécie de indiferença intratável por assuntos e coisas em geral, nem por isso deixava de ser extremamente solene e séria" (POE, 1997, p. 214). Enquanto Hugh Tarpaulin tem uma índole mais galhofeira e "olhava seu camarada cato com um sentimento meio de espanto, meio de zombaria" (POE, 1997, p. 214).

Essa mescla de humano e animal presente na caracterização das personagens é relevante para o desfecho da trama, pois eles são os representantes de um mundo, no qual os corpos se mesclam aos de outros reinos, rompendo as barreiras entre os corpos e o mundo em construção. A ambivalência da imagem grotesca dos corpos traz para a narrativa um tom satírico e humorístico, pois os horrores 
da peste são tratados a partir de uma imagem caricata tanto dos marinheiros quanto do reino de Eduardo III. O rei, apesar de ter instaurado a ordem real na Inglaterra, tem seu reino invadido por um inimigo de outra ordem, com o qual ele está impossibilitado de lutar valendo-se da força bruta, uma vez que:

Ressoava por toda a Inglaterra, e mais especialmente na metrópole, o espantoso grito de: "Peste! A cidade estava em grande parte despovoada, e naqueles horríveis bairros das vizinhanças do Tâmisa, [...] o Demônio da Peste, tinha como se dizia, seu berço, a Angústia, o Terror e a Superstição passeavam, como únicos senhores, à vontade. (POE, 1987, p. 215)

Londres encontra-se dividida devido à contaminação pela peste e nas proximidades do Tâmisa, devido ao foco da doença, os bairros convertem-se em um cenário angustiante dominado pelo medo, o terror e superstição. A inserção nos domínios da peste ocorre quando Legs e Hugh Tarpaulin, após se embriagarem na taberna do "Alegre Marinheiro", fogem para não pagar a conta. Durante a fuga, rompem uma tosca barreira de madeira, que separava os bairros mais atingidos pela epidemia do restante da cidade, penetrando, assim, no espaço em que a peste é soberana.

A entrada em um ambiente inóspito, durante a madrugada, numa atmosfera de névoa, perde o invólucro de horrível porque se eles não estivessem "tão embriagados, a ponto de haverem perdido o senso moral, o horror de sua situação lhes teria paralisado os passos vacilantes" (POE, 1997, p. 215). A barreira, sinaliza o limite que separa as duas partes de um cosmo, um em que a peste ainda não adentrou e aquele no qual seus efeitos maléficos reinam 
soberanamente. A tosca armação, ou seja, o mecanismo criado pelas mãos humanas para impor a ordem num lugar em que impera o caos, teria o suposto poder de impedir a disseminação do vírus, o qual, na trama narrativa está personificado por meio do nome grafado em maiúsculas como o Demônio da Peste.

O cenário e a atmosfera fúnebre não despertam o medo em Legs e Hugh Tarpualin, porque:

Não estava no poder de imagens, sensações ou obstáculos como esses deter a corrida de homens que, naturalmente corajosos e, especialmente naquela ocasião, repletos de coragem e de hummingstuff, teriam ziguezagueado, tão eretos quanto Ihes permitia seu estado, sem temor até, mesmo dentro das fauces da morte. (POE,1997, p. 216)

Este trecho da narrativa remete a visão crítica de Poe, a respeito do terror, expressa no Prefácio da coletânea Tales of the Grotesque and Arabesque ao afirmar que: "Se a base de alguns contos meus é o horror, então afirmo que o horror provém da alma". Na afirmação de Poe há uma distinção entre o trágico e o cômico, porque podemos observar que o horror, na concepção dele, provém das regiões mentais, dos medos e das fobias não suscitadas por elementos exteriores, mas por estados mentais que despertam esses sentimentos dos subterrâneos da alma.

Legs e Hugh Tarpualin são marinheiros acostumados a enfrentar o desconhecido e as noites tempestuosas, estão embriagados, e a bebida funciona como uma atenuante das sensações negativas, por despertar neles não as fobias, mas sensações de prazer e alegria. E devido à coragem e à embriaguez, caminham pelas ruas desertas e fétidas, onde carcaças, esqueletos e cadáveres 
intensificam a atmosfera e o cenário pestilencial, no qual "não era raro que a mão caísse sobre um esqueleto ou pousasse num cadáver ainda com carne" (POE, 1997, p. 216).

Nesse cenário fúnebre Legs ouve guinchos vindos do interior de um edifício sinistro, no qual há uma sala, onde está uma mesa e ao redor dela estão "seis indivíduos sentados em catafalcos" (POE, 1997, p. 216). Trata-se da corte do Rei Peste I, e os demais membros pertencem a família pestilencial, ou seja: a esposa do rei a Rainha Peste; o Arquiduque Peste-Ífero; o Duque Pest-Ilencial; o Duque Tem-Pestuoso e a Arquiduquesa Ana-Peste.

$\mathrm{Na}$ caracterização de cada um dos membros da corte, instaurada na casa mortuária, Poe explora partes do corpo grotesco tal como o nariz, a boca e os olhos, transformando as vítimas da peste em parte integrante de um reino, no qual a morte é trasvestida em um tipo de rei bufo e demoníaco e pestilento. $\mathrm{O}$ aspecto cadavérico e disforme desses seres suscita $\mathrm{O}$ horror porque, na caracterização de cada um deles, Poe introduz elementos e características próprias do grotesco, que marcam o entrecruzar das fronteiras entre o humano e os objetos, bem como, entre os reinos animal e vegetal, fazendo com que haja um rebaixamento do humano, por meio daqueles aspectos que cada um tem em comum.

A caracterização de cada um deles é feita de modo sumarizado, destacando justamente as partes do corpo que os distinguem entre si, mas que ao mesmo tempo os insere em um reino cujas fronteiras entre os corpos e os aparatos fúnebres se mesclam. O Rei Peste, presidente da mesa, tem o rosto açafroado e se destaca devido a: 
[...] uma fronte tão insólita e tão horrivelmente elevada que tinha a aparência de um boné ou coroa de carne acrescentada à cabeça natural. Sua boca, enrugada, encovava-se numa expressão de afabilidade horrível e seus olhos, bem como os olhos de todos quantos se achavam em torno à mesa, tinham aquele humor vítreo da embriaguez. Esse cavalheiro trajava, da cabeça aos pés, uma mortalha de veludo de seda negra, ricamente bordada [...]. Estava com a cabeça cheia de plumas negras mortuárias, que ele fazia ondular para lá e para cá, com um ar afetado e presunçoso. E na mão direita segurava um enorme fêmur humano, com o qual parecia ter acabado de bater em algum dos presentes para que cantasse. (POE, 1997, p. 218)

A descrição do rei, somada ao papel de comando por ele desempenhado, remete à imagem de um galo. O galo, no budismo tibetano, tal como afirmam Chevalier e Gheerbrant, é nefasta e figura no "centro da roda da existência" (1996, p. 521), significando desejo, ganância, apego e sede.

A reunião dos seis membros ao redor da mesa, somada à caracterização do rei e a simbologia que a imagem do galo encerra pode ser considerada uma metáfora da roda da vida, na qual o ciclo de morte e renascimento é considerado um fato natural. E, na simbologia da roda, nas figuras de animais presentes no entrono dela pode ser vista a lei dos renascimentos, imposta àqueles que dominam os desejos carnais (CHEVALIER; GHEERBRANT, 1996). Trata-se, portanto, de um funeral ambivalente, caracterizado "pela lógica original das coisas "ao avesso", "ao contrário", das perturbações constantes do alto e do baixo ("a roda")" (BAKHTIN, 1999, p. 10). 
Na reunião, de frente ao Rei, está a Rainha Peste, cuja hidropisia acentuada, deixou-a semelhante a um imenso pipote de cerveja-de-outubro. A aparência trágica, , decorrente da acumulação anormal de fluido, causada pela doença, vem à tona por meio da comparação da imagem do corpo deformado com um pipote de cerveja. Porém, a parte do corpo colocada em evidência é o rosto, e nele se destaca a proporção da boca: "Começando na orelha direita, rasgava-se, em aterrorizante fenda, até a orelha esquerda" (POE, 1997, p. 218). A hiperbolização da boca mostra a argúcia de Poe, uma vez que: "O rosto grotesco se resume afinal em uma boca escancarada, e todo o resto só serve para emoldurar essa boca, esse abismo corporal escancarado e devorador" (BAKHTIN, 1999, p. 277). Para que a boca venha a constituir uma das imagens do corpo grotesco, ela precisa dominar, ou seja, escancarar-se sobre o rosto que apenas Ihe serve de moldura. Na passagem em apreço, a boca adquire uma existência autônoma, revelando não apenas um movimento involuntário de um corpo dominado pela peste, mas também o rompimento de fronteiras com o mundo exterior, as quais são devoradas por ela.

Ao lado da Rainha Peste está a Arquiduquesa Ana-Peste, uma mocinha cocha, com sinais de tuberculose galopante, trajando uma larga e bela mortalha de cambraia indiana. Em seu rosto o nariz se destaca por ser: "[...] extremamente comprido, delgado, sinuoso, flexível e cheio de borbulhas" (POE, 1997, p. 218). O nariz, devido a proporção, caia sobre o lábio inferior, e a moça o move de um lado para o outro com a língua, tal como a tromba de um elefante. Segundo Wladimir Propp, A aproximação ou "a comparação com 
animais é cômica apenas quando serve para desvendar um defeito qualquer" (1992, p. 68). Ao singularizar o nariz como tromba, Poe não apresenta a personagem na forma de um animal, como é comum nas fábulas, mas aproxima-a do elefante pelo que há de comum entre ambos, ou seja, o nariz. O nariz da Arquiduquesa Ana-Peste não é o símbolo do discernimento, mas produto de um corpo atacado pela tuberculose e borbulhas, num estágio entre a vida e a morte e, portanto, não desperta o riso. Humano e animal mais uma vez se entrecruzam retirando o foco do lado terrível da morte e colocando-o sobre os traços fisionômicos que abrem as fronteiras entre mundo dos vivos e dos mortos, porque tal como afirma Bakhtin: "A morte está sempre relacionada ao nascimento, o sepulcro ao seio terreno que dá à luz. Nascimento-morte e mortenascimento são as fases constitutivas da própria vida" (1999, p. 43-44).

E, à esquerda da Rainha está o Arqueduque Pest-Iferous, um velho inchado, gotoso com imensas bochechas que "repousavam sobre os ombros como dois imensos odres de vinho do Porto" (POE, 1997, p. 219). Nele sobressaia o traje de cores vistosas, talhado em uma coberta de seda bordada, pertencente "àqueles gloriosos escudos que, na Inglaterra e noutros lugares, são ordinariamente suspensos, em algum lugar bem patente, nas residências de aristocratas falecidos" (POE, 1997, p. 219). O corpo pequeno e gotoso somado às bochechas enormes converte a imagem do velho em um tipo de porco, revelando a gula.

Ao lado do Arqueduque Pest-Iferous encontra-se o Duque PestIlential, vestido ceroulas de algodão e meias brancas, com o queixo e os braços atados por uma faixa de musselina, e cujas orelhas prodigiosas "arrebitavam-se espasmodicamente ao rumor das 
rolhas que espoucavam" (POE, 1997, p. 219). O gesto de arrebitar as orelhas assemelha-o ao cavalo.

Em frente dele está o Duque Tem-Pestuoso, trajando ceroulas e um ataúde mogno, cuja tampa apertava o rosto como se fosse um elmo. Embora $\mathrm{o}$ ataúde tivesse aberturas para os braços saírem, o Duque não conseguia sentar e permanecia reclinado em um cavalete. E seus enormes olhos esbugalhados reviravam "suas apavorantes escleróticas para o teto, num absoluto espanto de sua própria enormidade" (POE, 1997, p. 219). Além do aspecto de coisa conferido pelo caixão, Poe também enfatiza a parte do corpo dessa personagem que se abre para o mundo exterior, conferindo-lhe enormes olhos esbugalhados, revirados para o teto. Se por um lado o corpo encontra-se encaixotado, separado do mundo, por outro, os olhos esbugalhados rompem as fronteiras que delimitam os espaços e revelam o corpo em crescimento, ultrapassando os próprios limites.

A boca, o nariz, as orelhas, os olhos esbugalhados são as partes em que o corpo "ultrapassa-se a si mesmo, franqueia seus próprios limites" (BAKHTIN, 1999, p. 23). As deformações dos corpos das personagens postas em destaque são ambivalentes, porque revelam que os mesmos aspectos que ridicularizam os corpos rebaixando-os na escala natural à mesma posição ocupada pelos animais, por outro lado, atenuam o aspecto horripilante das deformações causadas e pela peste. As imagens típicas da cultura popular, inseridas na trama, retratam a amplitude do cenário de destruição e horror provocados pela epidemia de peste.

Intensificando a atmosfera de horror, nesse cenário às avessas, crânios servem de copos e um esqueleto humano, preso ao teto 
por uma das pernas amarradas em uma corda, faz as vezes de lustre e seu crânio "continha certa quantidade de carvão em brasa, que lançava uma luz vacilante, mas viva, sobre a cena [...]" (POE, 1997, p. 219). Poe emprega a imagem do esqueleto de maneira semelhante a que fizera Petronius, uma vez que no Satyricon o esqueleto presente em um banquete não simboliza a morte de uma pessoa em particular, mas a morte em geral, e a brevidade da vida e sua presença servem para excitar os convidados a desfrutarem intensamente os momentos de prazer (CHEVALIER; GHEERBRANT, 1996). A inserção da imagem do esqueleto, portanto, significa a personificação da morte, não como um estado definido, mas uma morte dinâmica que anuncia uma nova forma de vida e harmoniza-se com a reunião regada a bebida, semelhante à um ritmo fúnebre carnavalizado, no qual os doentes, próximos à morte, bebem e festejam.

O clímax da reunião ocorre quando Hugh se aproxima de Ana Peste e desperta o ciúme do Duque Tem-Pestuoso. E o Rei Peste bate o bastão, ou seja, um fêmur humano sobre a mesa e começa a discursar. Ao invés de um cetro de ouro e pedrarias, o rei usa um fêmur humano, metáfora das inúmeras vidas ceifadas pela peste, bem como pela fome decorrente do acúmulo de riquezas nos cofres. Indignado com sua pseudossabedoria, Legs indaga-o sobre quem seriam eles e o que faziam ali na loja do cangalheiro. $\mathrm{O}$ tom formal do Rei, para responder a pergunta do marinheiro, contrasta, a priori, com o teor da resposta:

[...] estamos aqui, esta noite, preparados por intensa pesquisa e acurada investigação, a examinar [...] as incompreensíveis qualidades e 
natureza desses inestimáveis tesouros do paladar, que são os vinhos, cervejas e licores desta formosa metrópole. Assim procedemos não só para melhorar nossa própria situação, mas para o bem estar verdadeiro daquela soberana sobrenatural que reina sobre todos nós, cujos domínios não tem limites e cujo nome é "Morte". (POE, 1997, p. 221)

A corte, ali reunida, está a serviço da morte e, portanto, no reinado do Rei Peste I figuram os cavaleiros do apocalipse, ou seja, sob os domínios da peste estão a morte, a fome, e a guerra. E, nesse palácio instalado na loja de cangalhos, as transposições de tons solenes para tratar de futilidades se opõem-se ao tom sério com que eram tratados os estragos feitos pela peste, pelos vícios, pela fome e por todos os infortúnios que sofriam a sociedade inglesa no decorrer do reinado de Eduardo III, período no qual também houve a consolidação do Parlamento inglês.

A assembleia composta por esses seres espectrais constrói um segundo mundo não oficial, um tipo de paródia da vida ordinária, um mundo ao revés. Nesse mundo às avessas, a assembleia do Parlamento se dá na loja de cangalhos e os parlamentares não estão empenhados em tomarem decisões sérias, mas em discutirem banalidades e se embriagarem. Poe cria uma mescla do lado sério da vida na corte com os aspectos grotescos presentes nos festejos realizados nos palácios, nos quais os trajes, a comida e a bebida assumiam dimensões abundantes.

As zombarias de Hugh Tarpaulin colocam os protagonistas em uma situação embaraçosa com o Rei Peste I, ao afirmar que o conhecia pelo nome de "Tim Hurlygruly, o palhaço!". O caráter zombeteiro dessa personagem retirou a máscara que encobria 
o lado bufo do rei, transformando gestos e palavras, até então supostamente sérias em um espetáculo que revelou o lado ridículo do monarca.

Na discussão, a menção do nome Davi Jones irrita o Rei Peste I. Davi Jones, segundo a lenda, era um marinheiro detentor de poderes diabólicos, como, por exemplo, prolongar a vida, com os quais atormentava os marinheiros fazendo com que chocassem contra os rochedos ou que participassem de missões perigosas. Segundo Sova (2001), o nome Davi Jones, cuja origem remete a uma variação da palavra duffy ou duppy, se refere a um espírito maligno do mar e também a Jonas, o profeta do Velho testamento.

Ao mencionar o nome Davi Jones, Poe dialoga com o imaginário popular, bem como com obras que antecederam a sua narrativa, como, por exemplo, As viagens de quatro anos do capitão George Roberts (1726) de Defoe e As aventuras do pescador Negro (1824) de Washington Irving e atualiza o poder conferido ao diabólico marinheiro de prolongar a vida. É a partir da menção do nome de Davi Jones que ocorre o desfecho do conto.

E por meio de a adoção de um tom grave, pelo Rei Peste I, para infligir uma pena jocosa a Hugh Tarpaulin, ou seja, a de beber um "galão de Black Strap" (POE, 1997, p. 221), um tipo de mistura de cachaça com melado, em louvor a prosperidade do reino e um só gole, intensifica o traço burlesco da suposta corte ali instaurada. A pena instaura o conflito e a força e a seriedade de caráter de Legs não permitem que ele se resigne perante um rei bufo. E nesse julgamento em que se tenta reinstalar a "ordem" pertencente ao mundo às avessas, Legs empurra o Rei Peste para dentro de um 
alçapão e o prende. Corre para o meio da sala e desinstala a ordem imposta ao puxar o esqueleto um tipo de lustre, pendurado sobre a mesa, e esmaga o crânio do homem gotoso. Em seguida revira a pipa de cerveja em que está seu companheiro, fazendo jorrar "um dilúvio de licor tão impetuoso, tão violento, tão irresistivel, que a sala ficou inundada [...] as mesas carregadas viraram de pernas para o ar" (POE, 1997, p. 223). Os marinheiros fogem em direção ao navio Free and Easy, levando com eles Rainha Peste e a Arquiduquesa Ana-Peste.

\section{CONSIDERAÇÕES FINAIS}

O conto "O Rei Peste" foi enquadrado por Poe na categoria de contos grotescos, ou seja, aqueles cujo efeito sobre o leitor é obtido por meio de um senso de humor sinistro e irônico. Nessa narrativa a ambivalência do estilo grotesco insere o tema da peste na ficção e a ficção na História, num processo dialógico no qual, ao mesmo tempo em que retrata os corpos deformados pela doença que os assolam ele chama a atenção para a necessidade de um processo contínuo de adaptação e maleabilidade das normas e costumes adotados pela sociedade.

A análise demonstrou que a crítica ao conto efetuada por Robert Louis Stevenson está associada a mescla do horror suscitado pelas imagens grotescas, sobretudo no que tange a atmosfera fúnebre e a deformação dos corpos, com e humor decorrente da transposição do tom solene para tratar situações burlescas. A ambivalência presente na narrativa ocorre em virtude do modo como Poe concebe e emprega o termo grotesco em dois planos distintos, ou seja, para designar "uma situação concreta, na qual a 
ordem do mundo saiu fora dos eixos", e também para qualificar o teor de histórias inteiras, "onde se narra o horripilante inconcebível, o noturno inexplorável e, às vezes, o fantasticamente bizarro" (KAYSER, 1986, p. 76).

O lado trágico do cenário desolado pela peste foi atenuado por meio da transposição do tom solene para o jocoso adotada pelo narrador, como, por exemplo, na descrição feita da barreira como tosca armação de madeira que separa os bairros de Londres acometidos pela peste das demais partes da cidade.

A escolha do que foi reproduzido da História, na ficção, é uma atitude subjetiva impregnada pela visão do crítico, a qual deixa transparecer a intenção do ficcionista de desautorizar a história oficial, realizada de duas formas: primeiro pela apropriação crítica de minúcias que colocam em evidência os sintomas da peste, transfigurando partes dos corpos dos enfermos fazendo com que sua aparência se aproxime a de animais; segundo pela subversão, feita através do tom humorístico e irônico que lhe permitiu criar um cosmo no qual a ordem imposta deixa ver a desordem instaurada pela delimitação de espaços que criam fronteiras entre os corpos e o mundo, mas não impedem a transmissão de doenças.

\section{REFERÊNCIAS}

BAKHTIN, Mikhail. A Cultura popular na Idade Média e no Renascimento: 0 contexto de François Rabelais. São Paulo - Brasíla: HUCITEC, 1999.

CHEVALIER, Jean; GHEERBRANT, Alain. Dicionário de Símbolos. Rio de Janeiro: José Olympio Editora, 1995.

COOKE, Jennifer. Legacies of Plague in Literature, Theory and Film. Basingstoke: Palgrave Macmillan, 2009.

KAYSER, Wolfgang. O Grotesco. São Paulo: Perspectiva, 1986. 
MENDES, Oscar (Org.). Nota Preliminar. In: POE, Edgar Allan. Ficção Completa, Poesia \& Ensaios. Rio de Janeiro: Nova Aguilar, p. 187-190, 1997.

POE, Edgar Allan. O Rei Peste. Conto Alegórico. In: POE, Edgar Allan. Ficção Completa, Poesia \& Ensaios. Oscar Mendes (Org.). Rio de Janeiro: Nova Aguilar, 1997.

SOVA, Dawn B. Edgar Allan Poe A to Z: The essential reference to his life and work. New York: Checkmark Books, 2001. 